\title{
Evaluation of Bitterness Suppression of Macrolide Dry Syrups by Jellies
}

\author{
Eriko TsujI, ${ }^{a}$ Takahiro UCHIDA, ${ }^{* a}$ Atsuko Fukui, ${ }^{b}$ Ryuta FunII, ${ }^{b}$ and Hisakazu SunADA ${ }^{c}$ \\ ${ }^{a}$ School of Pharmaceutical Sciences, Mukogawa Women's University; Koshien 9-Bancho, Nishinomiya, Hyogo 663-8179, \\ Japan: ${ }^{b}$ Ryukakusan Co., Ltd.; Higashi Kanda, Chiyoda-ku, Tokyo 101-0031, Japan: and ${ }^{c}$ Faculty of Pharmacy, Meijo \\ University; Yagotoyama, Tempaku-ku, Nagoya 468-8503, Japan. \\ Received August 19, 2005; accepted November 29, 2005; published online December 12, 2005
}

The purpose of this study was to evaluate the bitterness-suppressing effect of three jellies, all commercially available on the Japanese market as swallowing aids, on two dry syrups containing the macrolides clarithromycin (CAM) or azithromycin (AZM). The bitterness intensities of mixtures of the dry syrups and acidic jellies were significantly greater than those of water suspensions of the dry syrups in human gustatory sensation tests. On the other hand, the mixture with a chocolate jelly, which has a neutral $\mathrm{pH}$, was less bitter than water suspensions of the dry syrups. The bitterness intensities predicted by the taste sensor output values correlated well with the observed bitterness intensities in human gustatory sensation tests. When the concentrations of CAM and AZM in solutions extracted from physical mixtures of dry syrup and jelly were determined by HPLC, concentrations in the solutions extracted from mixtures with acidic jellies were higher than those from mixtures with a neutral jelly (almost 90 times higher for CAM, and almost 7-10 times higher for AZM). Thus, bitterness suppression is correlated with the $\mathrm{pH}$ of the jelly. Finally, a drug dissolution test for dry syrup with and without jelly was performed using the paddle method. There was no significance difference in dissolution profile. It was concluded the appropriate choice of jelly with the right $\mathrm{pH}$ is essential for taste masking. Suitable jellies might be used to improve patient compliance, especially in children. The taste sensor may be used to predict the bitterness-suppressing effect of the jelly.

Key words swallowing aid; jelly; bitterness; macrolide; dry syrup; taste sensor

Some of the main reasons for noncompliance with dosage instructions in infants and children are unsavory or bitter taste, formulations which are very powdery, and multiple dosings. ${ }^{1-3)}$ Powdery medicines in particular often taste unpleasant, even in taste-masked formulations. Recently, a number of jelly products have been developed that aim to improve compliance by aiding swallowing. ${ }^{4-7)}$ When the drug is incorporated in the jelly product, swallowing is made easier due to its moderate adhesion and liquidity while drug adsorption by the tongue is prevented, and bitterness perception is thereby decreased. Fukui has reported on the physicochemical characteristics of jellies, such as viscosity, strength, loss of water content, and its effect on swallowing. ${ }^{8)}$ There are, however, few reports in which jellies have been evaluated from the viewpoint of bitterness suppression.

We have already quantitatively evaluated the bitterness of several human pharmaceuticals using the taste sensor. ${ }^{9,10)}$ In particular, the relation between the concentration of various pediatric antibiotics and their bitterness intensity has been investigated, as well as the effect of mixing the drugs with various beverages on palatability. The usefulness of the taste sensor in predicting the bitterness of these antibiotic mixtures was confirmed. ${ }^{1-14)}$

In the present study, we evaluated bitterness suppression of dry syrups containing the macrolides clarithromycin (CAM) or azithromycin (AZM), both of which are extremely bitter, by the addition of jellies, using gustatory sensation tests and the taste sensor. The concentrations of CAM and AZM in solutions extracted from physical mixtures of dry syrup and jelly were determined by HPLC. Finally, dissolution tests were performed on a mixture of dry syrup and chocolate jelly and on dry syrup alone to confirm the equality of dissolution profile.

\section{Experimental}

Materials Two macrolide dry syrups were used in this study: clarithromycin, CLARITH ${ }^{\circledR}$ dry syrup for pediatric use (CAMD), purchased from Taisho Toyama Co., Ltd., Tokyo, Japan, and azithromycin, ZITHRO$M C^{\circledR}$ Fine Granules for Pediatric Use (Commercially available from December, 2004) (AZMD) purchased from Pfizer Pharmaceutical Co., Ltd., Tokyo, Japan. The following jellies were used in this study: Okusurinometane'Chocolate (Chocolate jelly) (Ryukakusan Co., Ltd., Tokyo, Japan), Paste-jouno oblate·Plane (Paste jelly) (Sanwa kagaku kenkyusho Co., Ltd., Aichi, Japan), Water Jelly ${ }^{\circledR} \cdot$ Muscat (Water jelly) (Ohki Co., Ltd., Tokyo, Japan). All other reagents were of special reagent grade.

Sample Preparation For human gustatory sensation testing, $\mathrm{pH}$ measurement, concentration measurements, and the dissolution test, $10 \mathrm{ml}$ of the jelly (or water as control) was mixed with $0.2 \mathrm{~g}$ of CAMD or AZMD uniformly for $30 \mathrm{~s}$ with spoon. Two additional mixtures of CAMD and chocolate jelly, containing $0.13 \mathrm{~g}$ and $0.4 \mathrm{~g}$ of CAMD, were prepared to examine the effect of the ratio of the amount of chocolate jelly to CAMD on bitterness. For the taste sensor samples, $0.1 \mathrm{mmol}$ of $\mathrm{KCl}$ was added to improve the sensitivity of the sensor.

Gustatory Sensation Tests Gustatory sensation tests were performed using the method of Katsuragi et al. ${ }^{15)}$ The standard quinine hydrochloride concentrations used were $0.01,0.03,0.10,0.30$, and $1.00 \mathrm{~mm}$ and the corresponding bitterness scores were defined as $0,1,2,3$, and 4 , respectively. Before testing, the well-trained healthy adult volunteers $(n=5$ or 6$)$ were asked to keep the standard samples in their mouths, and told their concentrations and bitterness scores. After tasting $2 \mathrm{ml}$ of a test drug sample, they were asked to give the sample a bitterness score. The significance of the differences between the bitterness scores was analyzed using Mann-Whitney's $U$ test.

Sensor Measurement and Data Analysis The taste sensor system, SA402B of Intelligent Sensor Technology Co., Ltd., Atsugi, Japan, consists of a sensor component, a mechanically controlled robot arm, and a computer for data analysis. The detecting sensor part of the equipment consists of eight electrodes composed of lipid/polymer membranes which transform information about substances producing taste into electrical signals. The difference between the electric potential of the sensor electrode and that of the reference electrode is measured by means of a high-input impedance amplifier connected to a computer. The taste sensor methodology and sensor membrane components used in the present study are essentially the same as those described in a previous paper. ${ }^{13)}$

Samples (mixtures of $0.8 \mathrm{~g}$ of dry syrup and $40 \mathrm{ml}$ of jelly or water) were evaluated in the following manner. The electrode is first dipped into the ref- 


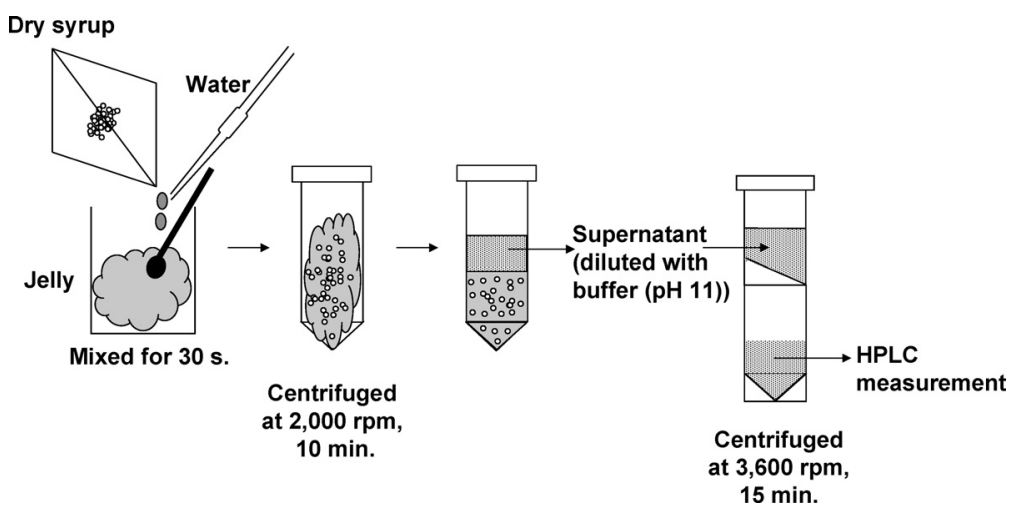

Fig. 1. Determination of Drug Concentration in Solutions Extracted from Mixtures of Dry Syrup and Jelly

erence solution $(\mathrm{Vr})$ and then into the sample $(\mathrm{Vs})$. The relative sensor output is represented as the difference $(\mathrm{Vs}-\mathrm{Vr})$ between the potentials of the sample and the reference solution. The electrode is rinsed with $40 \mathrm{ml}$ of a fresh reference solution three times for $6 \mathrm{~s}$, before being dipped into a fresh reference solution for $30 \mathrm{~s}$. The detected potential of the reference solution is defined as $\mathrm{Vr}^{\prime}$. The difference $\left(\mathrm{Vr}^{\prime}-\mathrm{Vr}\right)$ between the potentials of the reference solution before and after sample measurement is defined as CPA (change of membrane potential caused by adsorption) and corresponds to aftertaste. The electrode is rinsed with $120 \mathrm{ml}$ of another fresh reference solution for $6 \mathrm{~min}$. Each measuring time for $\mathrm{Vr}$, $\mathrm{Vs}$, and $\mathrm{Vr}^{\prime}$ was set at $30 \mathrm{~s}$.

In the present study, relative sensor output values and CPA values were used to predict bitterness. The data were analyzed with S-PLUS 2000J (Mathematical Systems Inc., Tokyo, Japan).

Measurements of $\mathbf{p H}$ The $\mathrm{pH}$ of jelly alone and physical mixtures of dry syrup and jelly were measured immediately after preparation using a $\mathrm{pH}$ meter (HORIBA, F-21, Kyoto, Japan).

Determination of Drug Concentration in Solutions Extracted from Mixtures of Dry Syrup and Jelly The determination of the concentration of drug in solutions extracted from mixtures of dry syrup and jelly was performed as shown in Fig. 1. After mixing the dry syrup and jelly for $30 \mathrm{~s}$, $2 \mathrm{ml}$ water were added and the solution was mixed for a further $30 \mathrm{~s}$. The mixture was centrifuged at $2000 \mathrm{rpm}$ for $10 \mathrm{~min}$, and the supernatant was diluted with buffer $\mathrm{pH} 11$ (2-fold for chocolate jelly, 10-fold for paste jelly and water jelly). A $1.5-\mathrm{ml}$ sample of this solution was prepared by ultrafiltration, and the concentrations of CAM or AZM in the filtered solution were determined using HPLC. For the HPLC, $100 \mu \mathrm{l}$ was injected onto a chromatograph (Shimadzu LC-10AT, Kyoto, Japan) equipped with a UV detector (Shimadzu SPD-10A, Kyoto, Japan), an integrator (Shimadzu C-R7Ae plus, Kyoto, Japan) and a reverse-phase column (Asahipak-ODP-50 4E, $4.6 \mathrm{~mm}$ i.d. $\times 250 \mathrm{~mm}$, Showa denko, Tokyo, Japan). The column temperature was set at $40^{\circ} \mathrm{C}$. The following mobile phase system was used: $40 \mathrm{mmol} / 1 \mathrm{~K}_{2} \mathrm{HPO}_{4}$ solution (with $10 \%(\mathrm{w} / \mathrm{v}) \mathrm{KOH}$ solution, $\mathrm{pH} 11)$ : acetonitrile $=2: 3$. The flow rate was $1.0 \mathrm{ml} / \mathrm{min}$. The wavelength was set at $215 \mathrm{~nm}$. The significance of the differences between the concentrations of samples was determined using Tukey's test or Dunnet's test.

Dissolution Test The in vitro dissolution profile of CAM and AZM from mixtures of dry syrup and chocolate jelly were determined according to the paddle method (Japanese Pharmacopoeia (JP), XIV). The dissolution medium was phosphate buffer solution, warmed to $37^{\circ} \mathrm{C}$, with the $\mathrm{pH}$ adjusted to 4 or 6.8 . The paddle speed was set at $100 \mathrm{rpm}$. The mixtures of $0.2 \mathrm{~g}$ of CAMD or AZMD and $10 \mathrm{ml}$ of jelly were suspended in $900 \mathrm{ml}$ solution, and $5 \mathrm{ml}$ samples were withdrawn at $1,5,10,30,60 \mathrm{~min}$. The samples were filtered through a membrane filter, pore size $0.45 \mu \mathrm{m}$, and the concentrations of CAM and AZM in the filtrate were determined by HPLC.

\section{Results and Discussion}

Relationship between the Bitterness Intensity Obtained in Gustatory Sensation Test and That Predicted by the Taste Sensor for Mixtures of Dry Syrup and Jelly Figure 2 shows the relationship between the bitterness intensity evaluated in gustatory sensation tests and that predicted by the taste sensor for mixtures of dry syrup and jelly.

In human gustatory sensation tests, bitterness was evalu-
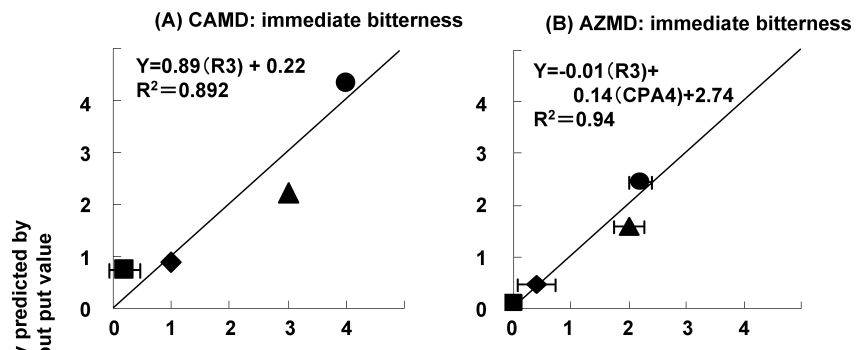

(C) CAMD: after-bitterness

(D) AZMD: after-bitterness
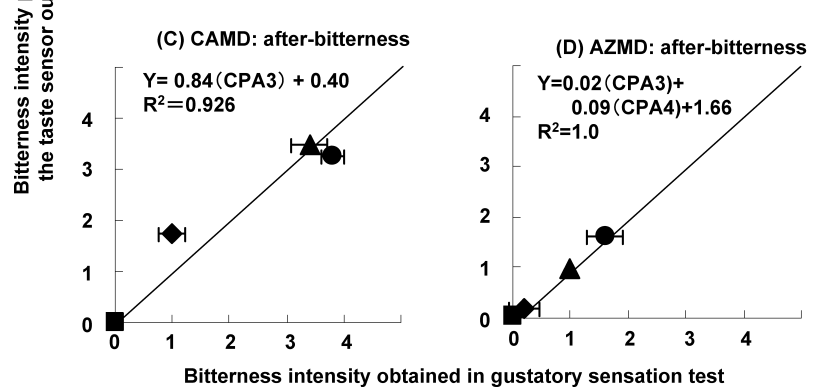

Fig. 2. Relationship between the Bitterness Intensity of Mixtures of Dry Syrup and Jelly Obtained in Human Gustatory Sensation Tests $(n=5)$ and Those Predicted from Taste Sensor Output

$\bullet$, water; $\mathbf{\square}$, chocolate Jelly; $\boldsymbol{\Delta}$, paste Jelly; $\bullet$, water Jelly.

ated at two time points: when the sample had been in the mouth for $5 \mathrm{~s}$, which we termed 'immediate bitterness', and directly after the sample had been ejected from the mouth, after rinsing with water, which we termed 'after-bitterness'. The immediate bitterness of a CAMD water suspension (control) was 1.0 in gustatory sensation tests (Fig. 2A), while that of mixtures of CAMD and chocolate jelly, paste jelly and water jelly were $0.2,3.0$, and 4.0 , respectively. The immediate bitterness of an AZMD water suspension (control) was 0.4 in gustatory sensation tests (Fig. 2B), while those of mixtures of AZMD and chocolate jelly, paste jelly and water jelly were $0,2.0$, and 2.2 , respectively. Thus, the paste and water jellies greatly enhanced the bitterness of both dry syrups, while the bitterness of mixture of chocolate jelly and AZMD (Commercially available from December, 2004) was successfully suppressed compared with that of water suspension of AZMD even though the bitterness of water suspension of AZMD was not so severe. A similar tendency was confirmed for after-bitterness (Figs. 2C, D).

Bitterness intensity was predicted by regression analysis of the output value of the taste sensor. For the immediate and after-bitterness of CAMD, relative values (R) and CPA val- 
ues (CPA) of channel 3 (the channel that responded best to the macrolide antibiotics) were used in the analysis. ${ }^{11)}$ As a result, a good correlation was confirmed between the actual bitterness obtained in the gustatory sensation test and the predicted bitterness obtained from the sensor; the correlation coefficient was 0.892 (immediate bitterness) and 0.926 (after-bitterness), as shown in Figs. 2A and C, respectively. The discrepancy between observed and predicted bitterness might be caused by difference of adsorption characteristics of drug on lipid-bilayer membrane of the receptor on human tongue and on the sensor membrane. We have to dissolve this issue by modifying the component of the sensor membranes in the future.

For the bitterness of AZMD, the CPA of channel 4 was also used in the analysis. A good correlation was confirmed between actual bitterness obtained in the gustatory sensation test and that predicted by the taste sensor; the correlation coefficient was 0.94 (immediate bitterness) and 1.0 (after-bitterness), as shown in Figs. 2B and D, respectively.

Therefore, the taste sensor was able to predict the bitterness not only of liquid and suspension samples but also of mixtures such as that of dry syrup and jelly.

Bitterness Suppression by Jellies As described above, the paste and water jellies greatly enhanced bitterness while the chocolate jelly suppressed bitterness, compared with the water suspension of the dry syrups. The $\mathrm{pH}$ of the jelly is thought to be the reason for this effect. Co-administration of any acid drink, such as orange juice, with the dry syrup will make the product taste more bitter, because macrolides are basic drugs. ${ }^{13,14)}$

In order to examine whether the $\mathrm{pH}$ of the jelly affects the bitterness-suppressing effect, the $\mathrm{pH}$ of the jelly alone, the $\mathrm{pH}$ of a mixture of dry syrup and jelly, and the concentration of drug in the solution extracted from the mixture of dry syrup and jelly, were measured as follows:

pH Measurement of Jelly Alone and Mixtures of Dry Syrup and Jelly As shown in Fig. 3, the $\mathrm{pH}$ of the chocolate jelly was 6.4, almost neutral, while in mixtures of CAMD (or AZMD) and chocolate jelly the $\mathrm{pH}$ shifted to 7.3 (or 8.2), respectively, because of the basic components in the dry syrup product. ${ }^{16,17)}$ This fact suggests that the solubility of CAM or AZM in chocolate jelly was low, since solubility of basic drugs increases as $\mathrm{pH}$ decreases.

On the other hand, the pHs of the paste jelly and the water jelly were 3.8 and 3.7, respectively, and mixtures of these jellies with CAMD (or AZMD) maintained their acidity (4.8 and 4.6 for CAMD, and 5.1 and 4.6 for AZMD, respectively). It is probable that the $\mathrm{pH}$ of these mixtures remained acidic due to the buffering capacity of these acidic jellies. This result suggests that the mixture of an acidic paste or water jelly with the dry syrup enhanced the dissolution of the CAM and AZM.

Drug Concentrations in Solutions Extracted from Dry Syrup/Jelly Mixtures Table 1 shows the concentration of the drug in solutions extracted from mixtures of CAMD or AZMD and jelly. The concentration of CAM in water suspensions of CAMD (as control) was $18.1 \mu \mathrm{g} / \mathrm{ml}$, while concentrations of CAM in solutions extracted from mixtures of CAMD with chocolate, paste, and water jelly mixtures were $13.7 \mu \mathrm{g} / \mathrm{ml}, 1178.2 \mu \mathrm{g} / \mathrm{ml}$ and $1374.8 \mu \mathrm{g} / \mathrm{ml}$, respectively. In other words, the concentrations of CAM in the solutions

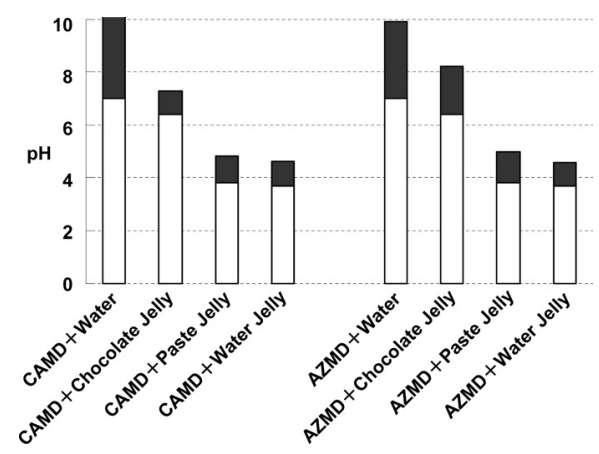

Fig. 3. The pH of Jelly Alone and Mixtures of Dry Syrup and Jelly

$\square$, jelly alone; $\mathbf{\square}$, mixture of dry syrup and jelly.

Table 1. Drug Concentrations in Solutions Extracted from Mixtures of Dry Syrup and Jelly

\begin{tabular}{clc}
\hline \hline & & Concentration $(\mu \mathrm{g} / \mathrm{ml})$ \\
\hline \multirow{2}{*}{ CAMD } & Water & $18.1 \pm 0.3$ \\
& Chocolate jelly & $13.7 \pm 0.4$ \\
& Paste jelly & $1178.2 \pm 62.6^{*, * *}$ \\
& Water jelly & $1374.8 \pm 90.6^{*, * *, * * *}$ \\
AZMD & Water & $33.1 \pm 1.4$ \\
& Chocolate jelly & $119.8 \pm 14.3$ \\
& Paste jelly & $1210.9 \pm 136.7^{*, * *}$ \\
& Water jelly & $876.5 \pm 141.3^{*, * *, * * *}$ \\
\hline
\end{tabular}

The values are mean \pm S.D. $(n=3)$. $* p<0.01$ compared with water suspension, $* * p<0.01$ compared with chocolate jelly sample, $* * * p<0.05$ compared with paste jelly sample, using Tukey's test.

from mixtures of CAMD and acidic jellies were almost 70 times that of the control, and almost 90 times that of the mixture with chocolate jelly. This result shows that acid jellies enhance the dissolution of basic CAM from CAMD. This is thought to be due to promotion of the dissolution of an acidsoluble polymer, aminoalkyl methacrylate copolymer E, which is present in the dry syrup to aid dissolution of CAM in stomach (below $\mathrm{pH}$ 5), and the fact that acid jellies enhance the solubility of basic CAM itself. ${ }^{16)}$ On the other hand, the concentration of CAM in the solution extracted from the mixture of CAMD and chocolate jelly was lower than the control. It was suggested that dissolution of CAM from the jelly was suppressed by the jelly network structure.

The concentration of CAM in the solution extracted from the mixture with the chocolate jelly was $13.7 \mu \mathrm{g} / \mathrm{ml}$; the corresponding immediate bitterness intensity in human gustatory sensation test was 0.2 . This result shows good agreement with a report that the bitterness threshold of CAM is $14 \mu \mathrm{g} / \mathrm{ml}^{16)}$ Similarly, the immediate bitterness intensity of the mixture of CAMD and the water jelly was 4 , and the corresponding concentration in the extracted solution was $1374.8 \mu \mathrm{g} / \mathrm{ml}$. This result agrees with our previous report that CAM solutions of $240 \mu \mathrm{g} / \mathrm{ml}$ or more have a bitterness intensity of $4{ }^{12)}$ However, the bitterness intensity of the mixture of CAMD and the paste jelly was 3, even though the concentration of CAM in the solution extracted from a mixture of CAMD and the paste jelly was $1178.2 \mu \mathrm{g} / \mathrm{ml}$.

The obtained high CAM concentration of the extracted sample might be different from actual CAM concentration in jelly. The considerably strong condition might result in a 
strong extraction of drug from the mixture of jelly. In addition, it was thought to be due to suppression of the dissolution of the CAM in the paste jelly in the mouth due to the higher viscosity of the paste jelly, and also to bitterness suppression by an additive in the paste jelly.

The AZM concentration in the water suspension of AZMD (control) was $33.1 \mu \mathrm{g} / \mathrm{ml}$, while the concentrations in solutions extracted from mixtures of AZMD and chocolate, paste, and water jellies were $119.8 \mu \mathrm{g} / \mathrm{ml}, 1210.9 \mu \mathrm{g} / \mathrm{ml}$, and $876.5 \mu \mathrm{g} / \mathrm{ml}$, respectively. These results show that the dissolution of basic AZM from AZMD is enhanced by mixing the dry syrup with acidic jellies, for the same reasons discussed for CAMD above.

However, the concentration of AZM $(119.8 \mu \mathrm{g} / \mathrm{ml})$ in the solution extracted from the mixture of AZMD and chocolate jelly was four times higher than the control $(33.1 \mu \mathrm{g} / \mathrm{ml})$, while the bitterness intensity was lower. It is suggested that the dissolution of the AZM from the chocolate jelly in the mouth is suppressed by the network structure of the chocolate jelly, while its bitterness is suppressed by the cocoa element in the chocolate jelly.

It can be concluded that dissolution of a drug from a dry syrup/jelly mixture is largely dependent on the $\mathrm{pH}$ of the jelly, which greatly influences bitterness suppression.

Influence of Ratio of Jelly to Dry Syrup on Bitterness Patients, especially infants, are likely to become noncompliant when large volumes of jelly have to be given. In order to examine the effect of the ratio of the amount of chocolate jelly to CAMD, concentrations of CAM in solutions extracted from different mixtures of chocolate jelly with CAMD were measured and compared with the results of gustatory sensation tests of the mixture.

When the chocolate jelly: CAMD ratio was 25,50 , and 77 , the bitterness intensities in gustatory sensation test were $0.7,0.2$, and 0 , respectively, and the corresponding concentrations of CAM in the solution extracted were $16.9 \mu \mathrm{g} / \mathrm{ml}$, $13.7 \mu \mathrm{g} / \mathrm{ml}$, and $8.5 \mu \mathrm{g} / \mathrm{ml}$, respectively (Table 2). Increasing the proportion of jelly therefore results in decreasing concentrations of drug in the extract, and decreasing bitterness in gustatory sensation tests.

If the chocolate jelly: CAMD ratio is over 25 , bitterness appears to be sufficiently suppressed not to cause an unpleasant taste.

Dissolution Test A dissolution test, using the paddle method, was performed in order to compare the dissolution of drug from the dry syrup alone and from a mixture of dry syrup and chocolate jelly, since there is a possibility that a difference in dissolution profile would cause reduced bioavailability.

The dissolution media were phosphate buffer solutions of pH 4 and 6.8 (CAM and AZM were unstable at $\mathrm{pH} 3$ or less). ${ }^{18)}$ Figure 4 shows the dissolution profile of CAM and AZM from dry syrup alone, and from a mixture of dry syrup and chocolate jelly.

CAMD alone shows a pH-dependent dissolution profile, dissolution $\%$ was $90 \%$ or more at $\mathrm{pH} 4$ at $30 \mathrm{~min}$, and $5 \%$ or less at $\mathrm{pH} 6.8$ at $60 \mathrm{~min}$, as shown in Fig. 4A. The corresponding dissolution rate constants, $k$, were $87.2\left(\times 10^{-3} \mathrm{~min}^{-1}\right)$ and $1.8\left(\times 10^{-3} \mathrm{~min}^{-1}\right)$, respectively, as shown in Table 3 . AZMD alone shows a $\mathrm{pH}$-dependent dissolution profile (Fig. $4 \mathrm{~B})$; $k$-values at $\mathrm{pH} 4$ and $\mathrm{pH} 6.8$ were $399.0\left(\times 10^{-3} \mathrm{~min}^{-1}\right)$
Table 2. Influence of Ratio of Jelly to Dry Syrup on Bitterness

\begin{tabular}{ccc}
\hline \hline $\begin{array}{c}\text { Chocolate jelly/ } \\
\text { CAMD }(\mathrm{ml} / \mathrm{g})\end{array}$ & $\begin{array}{c}\text { Bitterness intensity evaluated } \\
\text { by gustatory sensation test }\end{array}$ & $\begin{array}{c}\text { CAM concentration } \\
(\mu \mathrm{g} / \mathrm{ml})\end{array}$ \\
\hline 25 & $0.7 \pm 0.2$ & $16.9 \pm 0.6$ \\
50 & $0.2 \pm 0.2$ & $13.7 \pm 0.4^{* *}$ \\
77 & $0 \pm 0$ & $8.5 \pm 0.1^{* *}$ \\
\hline
\end{tabular}

Bitterness intensities are mean \pm S.E. $(n=6)$. CAM concentrations are mean \pm S.D $(n=3) . * * p<0.01$ compared with ratio 25 using Dunnet's test.

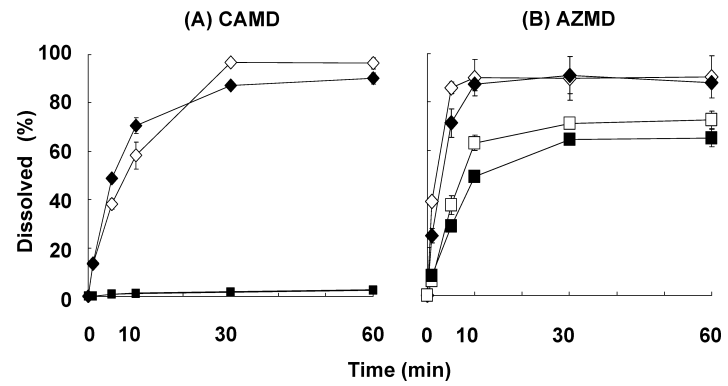

Fig. 4. Dissolution Profile of CAM and AZM from Dry Syrup Alone and from Mixtures of Dry Syrup and Chocolate Jelly

$\diamond$, dry syrup, $\mathrm{pH} 4$; $\diamond$, with chocolate jelly, $\mathrm{pH} 4$; $\square$, dry syrup, $\mathrm{pH} 6.8$; $\mathbf{\square}$, with chocolate jelly, $\mathrm{pH} 6.8$. The values are mean \pm S.E. $(n=3)$.

Table 3. Dissolution Rate Constants Calculated from Dissolution Data of Dry Syrup Alone and Mixture of Dry Syrup and Chocolate Jelly

\begin{tabular}{llc}
\hline \hline & & $k\left(\times 10^{-3} \min ^{-1}\right)$ \\
\hline pH 4 & CAMD & $87.2 \pm 15.2$ \\
pH 6.8 & CAMD & $1.8 \pm 0.3^{* *}$ \\
pH 4 & CAMD with chocolate Jelly & $128.1 \pm 6.9$ \\
pH 6.8 & CAMD with chocolate Jelly & $1.8 \pm 0.1^{* *}$ \\
pH 4 & AZMD & $399.0 \pm 30.5$ \\
pH 6.8 & AZMD & $133.3 \pm 19.8^{* *}$ \\
pH 4 & AZMD with chocolate Jelly & $260.2 \pm 44.7$ \\
pH 6.8 & AZMD with chocolate Jelly & $102.5 \pm 3.9^{* *}$ \\
\end{tabular}

The values are mean \pm S.D. $(n=3) . * * p<0.01$ compared with corresponding sample of pH 4 using Student's $t$-test.

and $133.3\left(\times 10^{-3} \mathrm{~min}^{-1}\right)$, respectively, as shown in Table 3 . Dissolution of AZM from AZMD was faster than that of CAM from CAMD. The $k$-values of mixtures of CAMD and chocolate jelly in dissolution media at $\mathrm{pH} 4$ and $\mathrm{pH} 6.8$ were $128.1\left(\times 10^{-3} \mathrm{~min}^{-1}\right)$ and $1.8\left(\times 10^{-3} \mathrm{~min}^{-1}\right)$, respectively, compared with $260.2\left(\times 10^{-3} \mathrm{~min}^{-1}\right)$ and 102.5 $\left(\times 10^{-3} \mathrm{~min}^{-1}\right)$, respectively, for mixtures of AZMD and chocolate jelly. Mixtures of both macrolide dry syrups and chocolate jelly showed a $\mathrm{pH}$-dependent dissolution profile, as did dry syrup alone.

The equivalence of the dissolution profiles was determined according to the 'Guideline for Bioequivalence Studies of Generic Products'. ${ }^{19)}$ Because the average dissolution \% of CAM or AZM from mixtures of dry syrup and chocolate jelly did not deviate by more than $15 \%$ from that of dry syrup alone, it was judged that the dissolution profiles of the mixtures of dry syrup and chocolate jelly were the same as for dry syrup alone.

Thus, it was concluded that the addition of chocolate jelly would not influence the bioavailability of the macrolides or their dissolution profile in the intestine. 


\section{Conclusions}

The bitterness of CAMD and AZMD was increased when the dry syrup was mixed with an acidic jelly and suppressed when mixed with a neutral jelly. The bitterness of the dry syrup/jelly mixtures could be predicted using a taste sensor. It was suggested that the different effects of the jellies were due to differences in the dissolution of the drugs (CAM and AZM) at an acidic $\mathrm{pH}$, because the concentration of the drug in the solution extracted from the mixture of dry syrup and acidic jelly was almost 90 times higher than that of the chocolate jelly for CAMD, and almost 7-10 times higher than that of the chocolate jelly for AZMD. The dissolution profile of the drug from a mixture of dry syrup and chocolate jelly was equivalent to that from dry syrup alone; it was therefore not expected that the chocolate jelly would influence the drug's dissolution profile in the intestine or its bioavailability.

Thus, the chocolate jelly suppressed the bitterness of the two antibiotics by making use of their physical properties. The effect of the suppression of bitterness by chocolate jelly seems superior to that of the flavor. The jelly could successfully protect direct exposure of dry syrup to the tongue as physical barrier. Whereas flavor could compete the dissolved drug on the bitterness-receptor site on tongue or stimulate sweetness-receptor. Nevertheless, its taste-masking efficiency does not seem so high since flavor could not compete high concentrated of dissolved drug and protect following bitterness perception completely.

Patients usually have to take $10-30 \mathrm{ml}$ of chocolate jelly with dry syrup at a time. This amount seems much larger than that of flavor. The dry syrup should be mixed with the jelly uniformly and gently within a limited time to avoid another drug release, and be taken immediately just after preparation of physical mixture.

The chocolate jelly with neutral $\mathrm{pH}$ could minimize solubility of basic macrolide drug in jelly and thereby restrict the bitterness perception of drug. The jelly may contribute to the improvement of patient compliance of medicines with bitter- ness.

Acknowledgements We thank Miss Sachie Okada, Mihoko Saeki and Yuhko Sakahira. This work was supported by grant-in-aids from the Ministry of Education, Science, Sports, Culture and Technology of Japan No.17590140 and No.17790043.

\section{References}

1) Iwai N., Acta Paediatr. Jpn., 39, 132-142 (1997).

2) Hoppe J. E., Blumenstock G., Grotz W., Selbmann H. K., Pediatr. Infect. Dis. J., 18, 1085-1091 (1999).

3) Nunn T., Williams J., Br. J. Clin. Pharmacol., 59, 674-676 (2005)

4) Hanawa T., Watanabe A., Tsuchiya T., Ikoma R., Hidaka M., Sugihara M., Chem. Pharm. Bull., 43, 872-876 (1995).

5) Kaneuchi M., Kohri N., Senbongi K., Sakai H., Iseki K., Yakugaku Zasshi, 125, 187-196 (2005).

6) Ando M., Kouzaki T., Higuchi F., Ichihashi T., Takeda M., Mizutani Y., Uesaka H., Yakuzaigaku, 60, 261-270 (2000).

7) Fukui A., Fujii R., Yonezawa Y., Sunada H., Chem. Pharm. Bull., 52, 298-302 (2004)

8) Fukui A., Fujii R., Sunada H. Yakuzaigaku, 60, 62-70 (2000).

9) Miyanaga Y., Tanigake A., Nakamura T., Kobayashi Y., Ikezaki H., Taniguchi A., Matsuyama K., Uchida T., Int. J. Pharm., 248, 207218 (2002).

10) Miyanaga Y., Inoue N., Ohnishi A., Fujisawa E., Yamaguchi M., Uchida T., Pharm. Res., 20, 1932-1938 (2003).

11) Uchida T., Tanigake A., Miyanaga Y., Matsuyama K., Kunitomo M., Kobayashi K., Ikezaki H., Taniguchi A., J. Pharm. Pharmacol., 55, $1479-1485$ (2003)

12) Tanigake A., Miyanaga Y., Nakamura T., Tsuji E., Matsuyama K., Kunitomo M., Uchida T., Chem. Pharm. Bull., 51, 1241-1245 (2003).

13) Ishizaka T., Miyanaga Y., Mukai J., Asaka K., Nakai Y., Tsuji E., Uchida T., Chem. Pharm. Bull., 52, 943-948 (2004)

14) Tsuji E., Takada M., Uchida T., Jpn. J. Pharm. Health Care Sci., 31, 186-193 (2005)

15) Katsuragi Y., Mitsui Y., Umeda T., Otsuji K., Yamasawa S., Kurihara K., Pharm. Res., 14, 720-724 (1997).

16) Yajima T., Nogata A., Demachi M., Umeki N., Itai S., Yonoki S., Nemoto M., Chem. Pharm. Bull., 44, 187-191 (1996).

17) Yajima T., Fukushima Y., Itai S., Kawashima Y., Chem. Pharm. Bull., 50, 147-152 (2002).

18) Ishii K., Katayama Y., Itai S., Ito Y., Hayashi H., Chem. Pharm. Bull., 43, 1943-1948 (1995).

19) Ministry of Health, Labour and Welfare, http://www.nihs.go.jp/drug/ be-guide/beguide1.html,web 22 December 1997. 